\title{
Brexit and health services
}

\author{
Authors: Tamara Hervey ${ }^{A}$ and Steve Peers ${ }^{B}$
}

David Cameron has committed to a referendum on a British exit from the European Union - the so-called Brexit - before the end of 2017, irrespective of whether or not the EU is prepared to renegotiate aspects of UK membership. Here we reflect on what the Brexit would mean for health services.

The EU's contributions to health services, health professionals and patients in the UK are wide-ranging. Some are well known as a result of media attention; some are more low-key, but nonetheless significant. There is barely an area of healthservices provision that is entirely untouched by the EU. In many instances, the UK was the driving force behind beneficial EU laws and policies. For example, the patients' rights directive, which secures mobility for patients across the EU, was inspired by litigation brought by British patients such as Yvonne Watts, who had a hip replacement operation in France, paid for by the NHS. Using their free European Health Insurance Cards, UK citizens can access emergency healthcare across the EU. Contrary to some claims, EU law actually protects the financial security of the NHS from unstructured patient movements around Europe, by allowing governments to defend NHS financial arrangements from unexpected costs of travelling patients trying to short-circuit waiting lists or access unproven treatments. Nothing in EU law affects the funding or structure of the NHS. Neither will EU membership mean that the Transatlantic Trade and Investment Partnership (if agreed) does so by the back door - as long as the UK government is willing to use its veto to defend the NHS.

Since the 1970s, the EU has regulated professional standards for access to medical professions, setting broad parameters for the training of doctors, nurses and midwives, among others. These shared and agreed rules on medical education allow medical professionals to work across the EU. Our doctors, should they wish to, can work in other EU states with minimum red tape. The UK has turned to other EU countries (and elsewhere in the world) to fill shortages of medical professionals and to cover unpopular shifts and places of work. Brexit would not mean that this setup would cease, but it would be more difficult to ensure equivalence of professional qualifications and individually negotiated agreements would be necessary either with each country or with the EU as a whole. If the UK is not

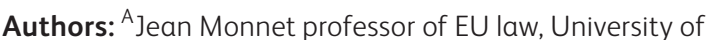
Sheffield, Sheffield, UK; B professor of EU law, University of Essex, Colchester, UK part of the EU, it will have to accept EU laws and policies as the starting point for those negotiations, rather than being present as the EU develops its rules on professional standards.

EU law protects patients by setting minimum standards for working-time rules across the EU. These rules prevent hospitals from forcing doctors and other medical professionals to work long hours and have informed discussions about on-call work and the quality of care that follows if medical professionals have to work without proper breaks or rest. Other EU countries train their junior doctors without such long hours, and the quality of their training is equivalent to ours. Health and safety at work rules coming from the EU protect all employees from workplace hazards.

Since the thalidomide scandal, the EU has regulated the safety of all pharmaceutical products marketed in the EU, by enforcing stringent pre-market authorisation rules and rules for post-market control, such as pharmacovigilance. Patients' rights organisations recognise the significance of these rules, which are designed to protect patients from unsafe drugs. The EU has been working actively with international organisations, particularly the International Medical Products Anti-Counterfeiting Taskforce, to secure the supply chain to Europe and to prevent falsified medicines reaching patients. For this kind of international problem, we have a greater chance of success if we negotiate en bloc, rather than alone.

To access the EU market, new health technologies (including biotechnology and nanotechnology) have to respect EU clinical trials laws. These laws not only protect patient safety through enforcing good clinical practice, but also respect European ideas of human dignity and human rights, such as the right to privacy and data protection. Trial participants, wherever they are, enjoy rights to protection under those EU laws. Our rules on use of medical data are informed by EU rules protecting human rights. Blood safety standards for the whole of the EU protect our patients, and we also have access to EU networks that help with organ donation. Our clinicians and biomedical researchers have access not only to EU data-sets, tissue banks, networks of collaborators and the like, but also to significant amounts of EU funding to support research. Losing this relationship would have highly damaging effects on our research hospitals and universities.

In the public health domain, EU rules on matters as wideranging as road infrastructure and transport safety, food and product safety, air and water quality, workplace health and safety and tobacco regulation have had tangible effects on population health. The EU's food regulations go beyond food safety, to include nutrition labelling and regulation of health 
claims (such as 'good for the heart'), which could mislead consumers into thinking foods are healthier than they are. Being in the EU allows the UK to share resources when scaling up brings clear benefits, such as the EU's rare diseases network, or when the nature of health problems necessitates a crossborder response, such as communicable-disease control.

Of course, exit from the EU would not preclude the UK from negotiating all these things separately with the different countries of the EU, or with the EU as a whole. But the outcome of those negotiations cannot be guaranteed, and the EU will not allow a non-member country to sit at the table when it develops standards in future. The UK will no longer be a participant in making policy, but will be 'taking' it instead. The costs of this approach would therefore greatly outweigh the benefits, and trying to negotiate from outside the EU would consequently leave our health services more vulnerable than they need to be.
Perhaps most importantly, however, health and the economy are intimately related. Economic decisions (such as a decision to follow austerity policies) have profound effects on population health, and healthcare systems. Resourcing is constrained; the gaps between rich and poor, healthy and unhealthy, the young and old and adults all increase; and above all the political and social debates about health become framed in narrower ways. The UK's global economic position, with the EU as its most significant trading partner, will remain unchanged whether we remain in the EU or not. If we are not around the table, we will not be able to influence EU political and economic decisions, laws, and policies.

Address for correspondence: Prof T Hervey, School of Law, University of Sheffield, Winter St, Sheffield S7 1ND, UK. Email: t.hervey@sheffield.ac.uk

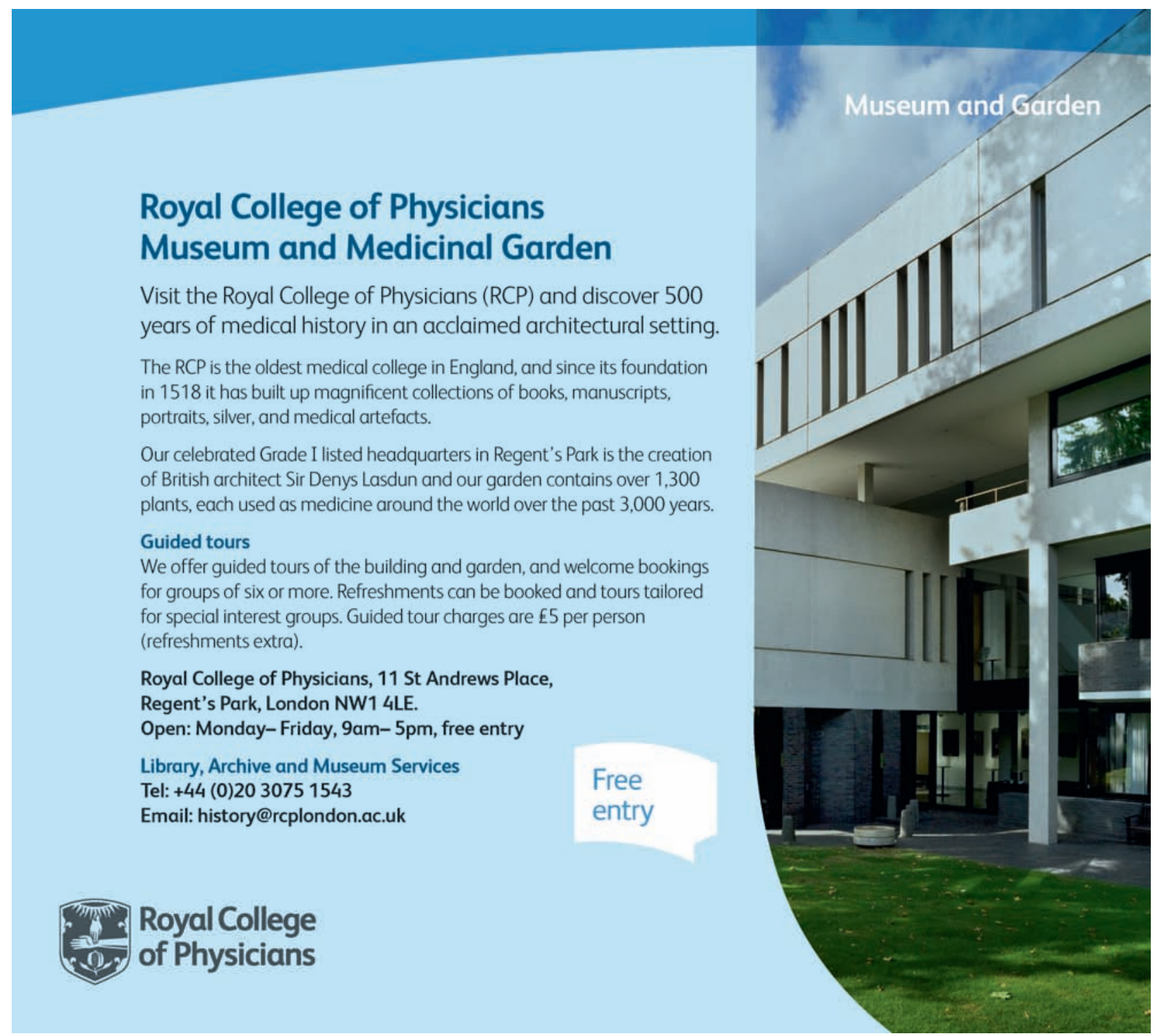

